\title{
Study the effects of radon inhalation on biomechanical properties of blood in rats
}

\author{
Mostafa Fawzy Eissa', Ashour M Ahmed1, Omar Abdel-Salam², Fayez Shahin ${ }^{1}$ \\ ${ }^{I}$ Department of Physics, Faculty of Science, Beni-Suef University, Beni-Suef, Egypt \\ ${ }^{2}$ National Research Centre, Dokki, Cairo, Egypt \\ [Presented at the $4^{\text {th }}$ African Regional IRPA congress (AFRIRPA04), which was held from September 13-17, 2014 in Rabat, Morocco. This paper \\ was reviewed and accepted by the scientific committee of the $4^{\text {th }}$ African Regional IRPA congress]
}

\section{Conference Proceeding}

\begin{abstract}
Purpose: To investigate the effect of inhalation radon gas $(\mathrm{Rn})$ on the biomechanical properties of red blood cell of rats. Methods: 20 young healthy adult male albino rats were divided into equally 4 groups. The first group (0) served as control group, while the other three groups (I, II and III) were exposed to Rn gas inside a chamber for 3, 5 and 7 weeks. The biomechanical properties of red blood cell of rats was performed by determine the rheological properties of blood and the osmotic fragility of red blood cells (RBCs). Results: The Rn doses received by every group of rats were found to $34.84,58.07$ and $81.30 \mathrm{mSv}$ for 3, 5 and 7 weeks respectively (based on 12 exposure hours per week). The obtained results indicate that the viscosity, consistency index, yield stress and aggregation index increase with Rn doses. The osmotic fragility curves of irradiated groups shift toward lower values of $\mathrm{NaCl}$ concentration. The dispersion of hemolysis $(\mathrm{S})$ increased, at the same time an average osmotic fragility $\left(\mathrm{H}_{50 \%}\right)$ decreased. Conclusion: The results indicates that the exposure to radon alters the mechanical properties of red blood cells membrane (permeability and elasticity) reflecting a change in its physiological properties. This mean that low levels of Rn gas are harmful to biological systems and the degree of damage was dose-dependent.
\end{abstract}

Keywords: Radon Gas, CR-39 Detector; Biomedical Properties; Red Blood Cells; Osmotic Fragility; Viscosity

\section{Introduction}

The exposures to ionizing radiations are producing harmful effects in the living organisms. Radon is the most important of all sources of natural radiation; about half radiation dose received by people being due to inhalation and ingestion of the $\mathrm{Rn}$ gas and its decay products. ${ }^{1} \mathrm{Rn}$ is originates from uranium deposited within the earth's crust. It can escape into the atmosphere through the fractures and openings in rocks. The emitted Rn gas is accumulated in air or dissolved in the groundwater.

Rn daughter can be deposited in the lungs through inhalation and they cause hazard effects. $\mathrm{Rn}$ and its daughters comprise complex radiation source emitting $\alpha, \beta$ particles and $\gamma$-rays. The majority of the energy deposited in biological systems is derived from the $\alpha$-particles component. ${ }^{2,3}$ Exposure to high concentrations of Rn and its daughters for long period leads to pathological effects such as lung cancer, leukemia, and kidney diseases. The indoor Rn has been determined to be the second leading cause of lung cancer after tobacco smoking. ${ }^{4}$ According to environmental protection agency (EPA) in 2003, Rn is estimated to cause about 21,000 lung cancer deaths per year in USA. ${ }^{5}$ However, the health effects arising from exposure to low-level $\mathrm{Rn}$ remain unclear. ${ }^{6}$ Also, the risks of $\mathrm{Rn}$ to organs, other than lung, are less well established. ${ }^{7}$ For such reasons, the present study aims to study the biological effects of Rn inhalation at low doses on body, especially the blood that plays an important role in human health.

Over the years, a large number of methods have been developed to measure Rn concentration. Of these methods, polyallyl-diglycol carbonate (CR-39) track detector is a standard tool for measuring $\mathrm{Rn}$ concentration. ${ }^{8}$ Also, it is easy to be handled and inserted in the inhalation chamber without causing any leakage. The dose equivalent of inhaled $\mathrm{Rn}$ and its daughters can be estimated if the $\mathrm{Rn}$ concentration in air is known as well as their equilibrium factor and the dose conversion factors.

\section{Methods and Materials}

\section{Rats exposure to radon gas}

In this work 20 young healthy adult male albino rats with average weight $150 \pm 10$ gm were used. The animals were 
divided into equally 4 groups. The first group (0) served as control group, while the other three groups (I, II and III) were exposed to $\mathrm{Rn}$ gas inside the chamber over 3, 5 and 7 weeks (based on 3 hours/day and 4 days/week). Figure 1 is shown the image of $\mathrm{Rn}$ chamber. For Rn dose measurements, eight CR-39 detectors were introduced in the $\mathrm{Rn}$ chamber with the animals for groups I, II and III. Can and bare method was used to determine the equilibrium factor $F_{\text {eq }}$ between radon and its daughters. ${ }^{9}$ It is defined as the ratio of the equilibrium equivalent concentration of radon over the actual activity concentration of radon in air. This factor was introduced to simulate the situation of disequilibrium. Two CR-39 detectors are exposing in diffusion chamber cup. One detector placed inside the chamber at its bottom that possesses a filter that only allows Rn gas to enter. The other was fixed outside the cup of the chamber therefore it is in contact with both the gas and its short progeny from the air. Directly after each exposure period, the animals was slightly anaesthetizes with ether and the blood samples were collected using heparinized syringe.

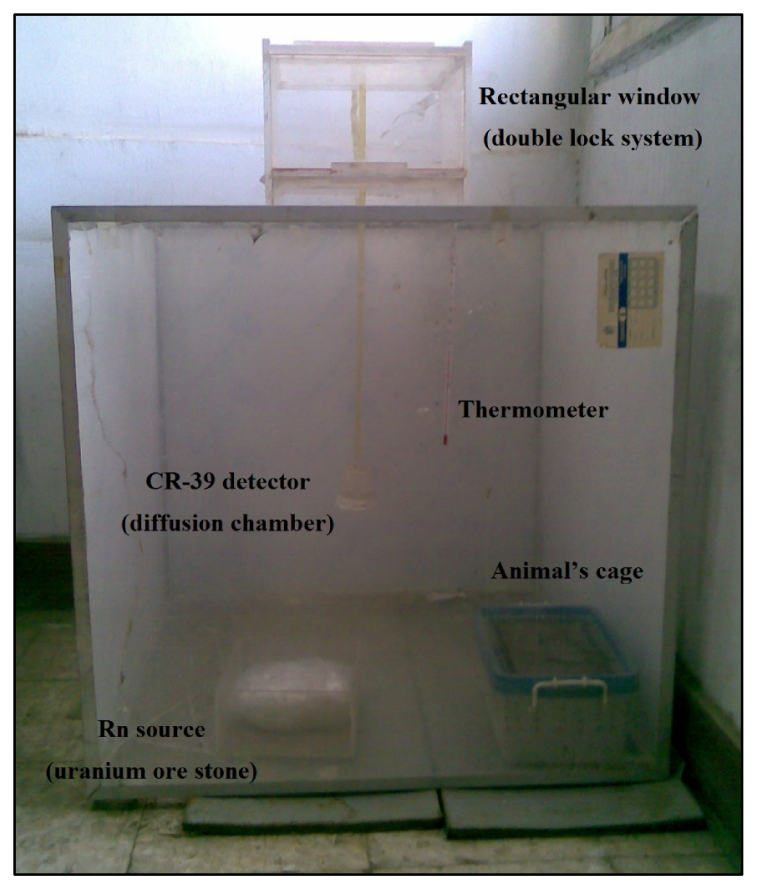

FIG. 1: Radon chamber.

\section{Radon doses measurement}

After exposures of the CR-39 detector sheets to Rn gas, alpha particles leaves a narrow trail of damage along its path is called latent track. The CR-39 detector sheets were collected and chemically etched to become easily seen the tracks under an optical microscope. ${ }^{10}$ The $\mathrm{Rn}$ concentration Co $\left(\mathrm{Bq} / \mathrm{m}^{3}\right)$ inside the chamber for CR-39 exposure time, $\mathrm{t}$ (days) can be obtaining by measuring the track density of the used filtered detector $\mathrm{D}_{\mathrm{o}}\left(\mathrm{T} / \mathrm{cm}^{2}\right)$ as following equation. ${ }^{11,12}$

$$
\mathrm{C}_{\mathrm{o}}=\mathrm{D}_{\mathrm{o}} / 0.215 \mathrm{t}
$$

The problem of determining the Radon's equilibrium factor, $F_{\text {eq, }}$ in terms of the track density ratio of opened D and filtered Do detector was solved by Planinic and Faj ${ }^{13}$

$$
F_{\text {eq }}=0.125 \mathrm{e}^{0.772\left(\mathrm{D} / \mathrm{D}_{0}\right)}-0.271
$$

The dose in term of working level month (WLM) was defined as ${ }^{14}$

$$
\mathrm{WLM}=\mathrm{WL} \frac{\mathrm{t}}{170}=\frac{\mathrm{F}_{\text {eq }} \mathrm{C}_{\mathrm{o}}}{3700} \frac{\mathrm{t}}{170}
$$

where, WL is the number of working level, $t$ is the exposure time (hour) which assumed that the exposure of $1 \mathrm{WL}$ for $170 \mathrm{~h}$ produce 1 WLM. WLM was converted into absorbed dose in $\mathrm{mSv}$ according to Nikezic et al. ${ }^{15}$

$\mathrm{WLM}=14.2 \mathrm{mSv}$

\section{Determination of the rheological properties of blood}

In this study, the rheological properties of blood were determined by using Brookfield DV-Ш Programmable Rheometer. The principle operation is to drive a spindle (which is immersed in the test fluid) through a calibrated spring. The viscous drag of the fluid against the spindle is measured by the spring deflection. Spring deflection is measured with a rotary transducer. The measuring range is determined by the rotational speed of the spindle, the size and shape of the spindle, the container the spindle is rotating in, and the full scale torque of the calibrated spring. According to principle of the cone-plate rheometer, rotation of a flat cone upon a plane surface (the plate) at different selected speeds of rotation (different shear rates) is take place. A small blood sample placed between the cone and the plate offers a resistance to the rotation of the cone and develops a torque determined by the shear stress in the blood (see Figure 2). Knowing the geometrical constants of the cone, and observing the rate of rotation and the torque can be separately calculated the shear stress (F) and shear rate (S) in the sample as follows ${ }^{16}$ :

$$
\mathrm{F}=3 \mathrm{M} / \mathrm{R}^{3} \mathrm{~S}=\omega / \beta
$$

Where, $M$ is the experimentally measured torque, $\Omega$ is the angular velocity and $\beta$ is the cone-pate angle.

By changing the number of revolutions per minute and thereby the rate of shear, a series of shear stress can be obtained, and by plotting these values against one another the rheological characteristics of the blood can then be defined directly in terms of a shear stress-shear rate diagram.

\section{Osmotic fragility}

Osmotic fragility of RBCs was determined by the method described by Dacie and Lewis. ${ }^{17}$

\section{Statistical analysis}

The mean and standard error were calculated for each group. Significantly difference from the control group was done using unpaired Student's t-test. The results t-test value is then checked on the standard t- table to find the significance level ( $P$-value). 


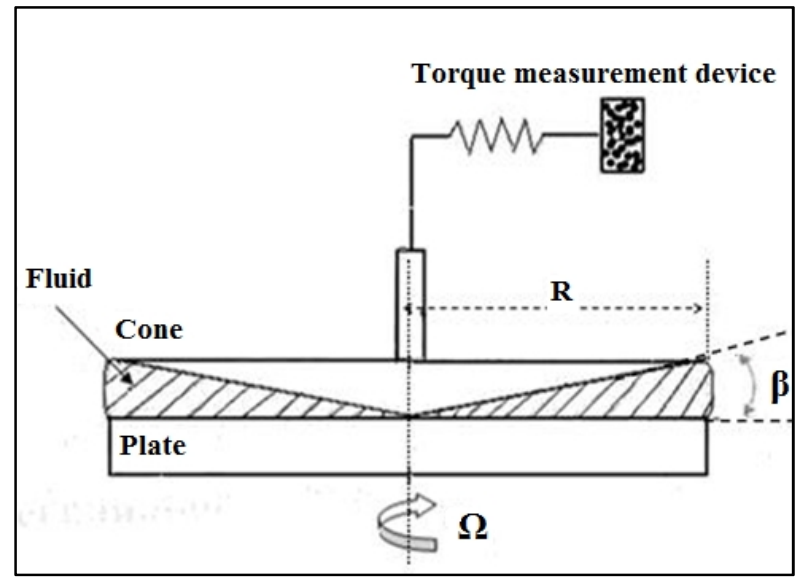

FIG. 2: Schematic diagram of a cone-plate viscometer.

\section{Results and Discussion}

\section{Radon doses measurements}

The results show that, the mean value of the $R n$ concentration is found to be $75.00 \pm 2.32 \mathrm{k} \mathrm{Bq} / \mathrm{m}^{3}$. The fluctuation in the $\mathrm{Rn}$ concentration is due to some small leakage of $\mathrm{Rn}$ during the insertion of the animal cage inside the chamber. For this reason the chamber is sealed for 3 days without exposure to compensate this leakage. The animals were exposed to a dose equal to 0.82 WLM per one week which is equivalent to an absorbed dose of $11.614 \mathrm{mSv}$. This means that $\mathrm{Rn}$ doses received by every group of rats were found to be 2.45, 4.09 and 5.72 WLM for 3, 5 and 7 weeks respectively (based on 12 exposure hours per week). The detailed of Rn measurements are listed in Tables 1 and 2.

\section{Rheological properties of blood}

Blood flow curve (viscosity against shear rate) shows that the blood viscosity decrease as shear rate increase. It is characterized by two regions:

1. Low shear rate region (shear rate up to $100 \mathrm{~s}^{-1}$ ): in this region the shear rate diagram shows a convex curvature with respect to the shear rate axis which appears as a reduction in the viscosity as the shear rate increases. This region can be characterized by the consistency index (m) and flow index (n), which can be calculated by the power fit of this range of the flow curve.

$$
\mathrm{F}=\mathrm{m} \mathrm{S}^{\mathrm{n}}
$$

2. The higher shear region (above $100 \mathrm{~s}^{-1}$ ): at which no further reduction in viscosity occurs. This region can be characterized by the apparent viscosity $(\eta)$ and yield stress $\left(F_{0}\right)$ which can be provided from the linear fit of the flow curve, applying Casson model.

$$
\sqrt{\mathrm{F}}=\sqrt{\mathrm{F}_{\mathrm{o}}}+\sqrt{\eta \mathrm{S}}
$$

Since the blood viscosity at low shear is greatly affected by the erythrocytes aggregation index which is defined as the ratio of viscosities at shear rate of 20 and $100 \mathrm{~s}^{-1} 18$.

$$
\text { Aggregation index }=\frac{\eta_{\text {at } 20 s^{-1}}}{\eta_{\text {at } 100 s^{-1}}}
$$

TABLE 1: The detail of Feq and WL measurements.

\begin{tabular}{cccccc}
\hline \hline $\begin{array}{c}\text { Time } \\
(\text { days })\end{array}$ & $\begin{array}{c}\mathrm{D} \\
\left(\mathrm{T} / \mathrm{cm}^{2}\right)\end{array}$ & $\begin{array}{c}\mathrm{D}_{0} \\
\left(\mathrm{~T} / \mathrm{cm}^{2}\right)\end{array}$ & $\begin{array}{c}\mathrm{C}_{0} \\
\left(\mathrm{kBq} / \mathrm{m}^{3}\right)\end{array}$ & Feq & WL \\
\hline 0.5 & 21780.606 & 8742.168 & 81.322 & 0.584 & 12.847 \\
1.0 & 36864.548 & 15972.173 & 74.289 & 0.471 & 9.468 \\
1.5 & 59784.757 & 22122.453 & 68.596 & 0.735 & 13.642 \\
2.0 & 85852.819 & 34624.624 & 80.522 & 0.576 & 12.550 \\
2.5 & 91136.415 & 37410.595 & 69.601 & 0.548 & 10.322 \\
3.0 & 105913.620 & 49075.237 & 76.085 & 0.390 & 8.029 \\
3.5 & 140254.332 & 59884.256 & 79.580 & 0.491 & 10.568 \\
4.0 & 168094.309 & 60232.361 & 70.037 & 0.806 & 15.274 \\
\multicolumn{7}{c}{ Mean values } & & 75.004 & 0.575 & 11.587 \\
\hline \hline S.E & & \pm 2.317 & \pm 0.061 & \pm 1.072 \\
\hline \hline
\end{tabular}

TABLE 2: The specification of the absorbed doses received by different rats groups.

\begin{tabular}{lccc}
\hline \hline Group & $\begin{array}{c}\text { Periods } \\
\text { Weeks }\end{array}$ & WLM & $\begin{array}{c}\text { Absorbed } \\
\text { Doses(mSv) }\end{array}$ \\
\hline I & 3 & 2.453 & 34.84 \\
II & 5 & 4.090 & 58.07 \\
III & 7 & 5.724 & 81.30 \\
\hline \hline
\end{tabular}

Blood flow curves for control and irradiated groups are shown in Figure 3. The blood viscosity increases with the irradiation dose. Figures 4 and 5 represent the power and Casson fitting, respectively for the shear rate - shear stress curves for the control and irradiated groups. The obtained results indicate that the viscosity, consistency index, yield stress and aggregation index increase with $\mathrm{Rn}$ doses as in Table 3.

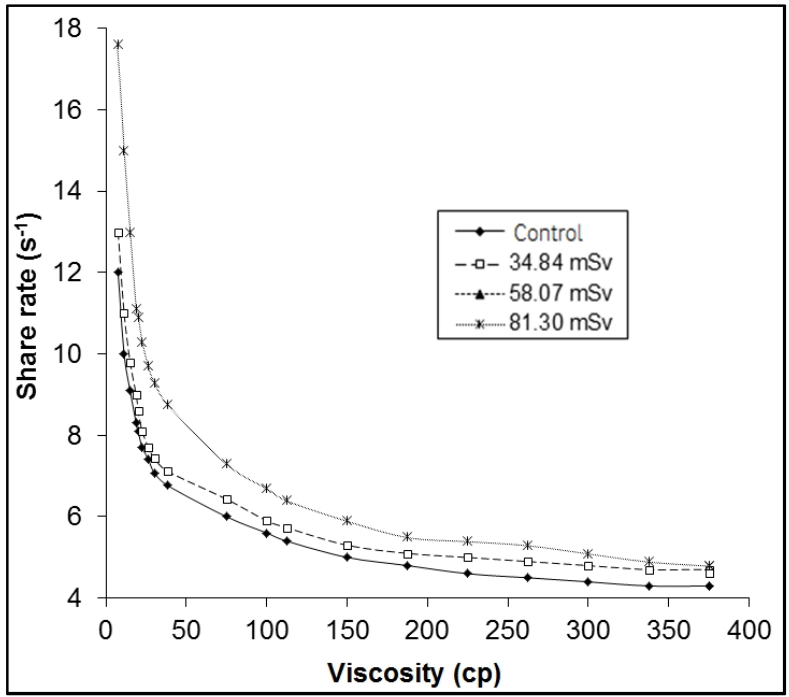

FIG. 3: Blood flow curves for control and irradiated groups. 


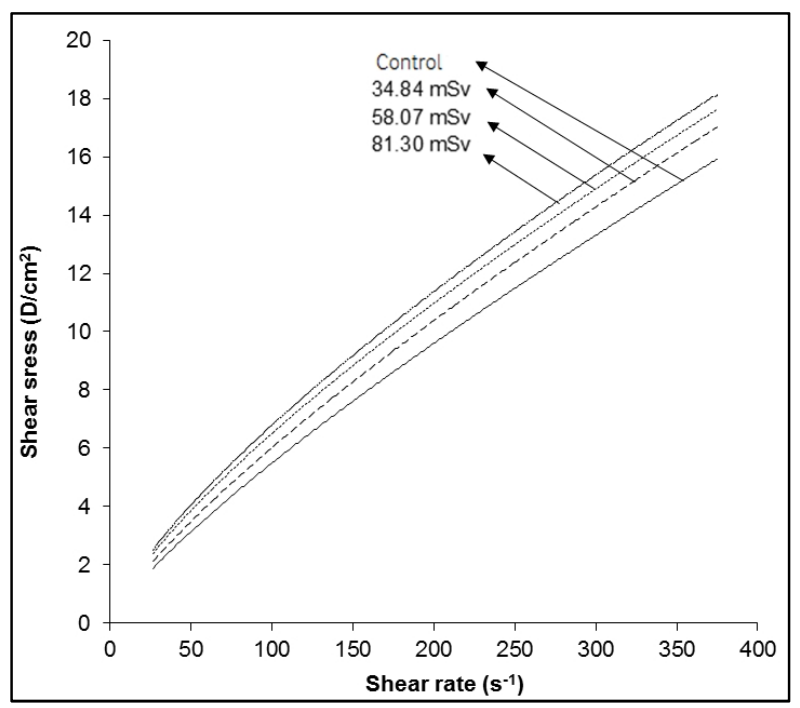

FIG. 4: The power fitting $\left(F=\mathrm{m} \mathrm{S}^{\mathrm{n}}\right)$ for the shear rate-shear stress curves for the control and irradiated groups.

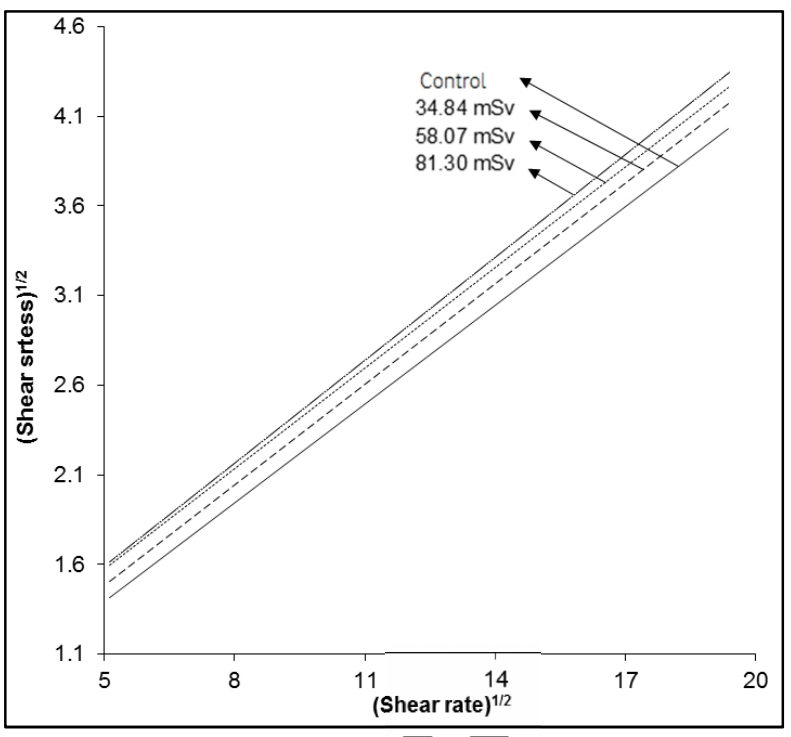

FIG. 5: The Cassion fitting $\left(\sqrt{\mathrm{F}}=\sqrt{\mathrm{F}_{0}}+\sqrt{\eta \mathrm{S}}\right)$ for the shear rate-shear stress curves for control and irradiated groups

TABLE 3: Viscosity parameters for control and irradiated groups.

\begin{tabular}{lllll}
\hline \hline Dose (mSv)/Parameters & Control group & $\mathbf{3 4 . 8 4}$ & $\mathbf{5 8 . 0 7}$ & $\mathbf{8 1 . 3 0}$ \\
\hline Viscosity $\eta(\mathrm{cp})$ & $3.241 \pm 0.141$ & $3.362 \pm 0.173$ & $3.668 \pm 0.105^{*}$ & $3.831 \pm 0.071^{* *}$ \\
Flow index N & $0.805 \pm 0.013$ & $0.786 \pm 0.016$ & $0.753 \pm 0.014^{*}$ & $0.742 \pm 0.018^{*}$ \\
Yield stress Fo $\left(\mathrm{D} / \mathrm{cm}^{2}\right)$ & $0.224 \pm 0.013$ & $0.298 \pm 0.01^{* *}$ & $0.403 \pm 0.021^{* * *}$ & $0.410 \pm 0.012^{* * *}$ \\
Consistency index m $(\mathrm{cp})$ & $13.448 \pm 0.905$ & $16.260 \pm 1.260$ & $20.100 \pm 2.104^{*}$ & $22.506 \pm 1.9877^{* *}$ \\
Aggregation index & $1.441 \pm 0.020$ & $1.452 \pm 0.029$ & $1.588 \pm 0.045^{*}$ & $1.631 \pm 0.026^{* * *}$ \\
\hline \hline
\end{tabular}

Data are means \pm S.E of 5 rats. Significant difference from control at $\mathrm{P}<0.05^{*}, 0.01^{* *}, 0.001^{* * *}$

Change $\%$ as compared to control value.

TABLE 4: The average osmotic fragility (H50\%), dispersion index (S) and the width (W), peak (P), center (Cmax) of the Gaussian distribution curves of the rate of hemolysis for control and irradiated groups.

\begin{tabular}{llllll}
\hline \hline \multicolumn{1}{c}{ Dose (mSv)/Parameters } & Control group & & \multicolumn{1}{c}{34.84} & \multicolumn{1}{c}{58.07} & \multicolumn{1}{c}{$\mathbf{8 1 . 3 0}$} \\
\hline Average osmotic fragility $\left(\mathrm{H}_{50 \%}\right)$ & $45.548 \pm 0.337$ & & $42.868 \pm 0.577^{* *}$ & $39.964 \pm 0.905^{* * *}$ & $38.883 \pm 0.962^{* * *}$ \\
Dispersion index (S) & $17.347 \pm 1.036$ & $18.644 \pm 1.856$ & $32.237 \pm 4.790^{*}$ & $33.274 \pm 2.543^{* * *}$ \\
Peak (P) & $68.776 \pm 2.452$ & $75.502 \pm 2.819$ & $60.799 \pm 3.981$ & $58.644 \pm 3.594^{*}$ \\
Center (Cmax) & $45.423 \pm 0.339$ & $42.572 \pm 0.949^{*}$ & $41.877 \pm 0.429^{* * *}$ & $39.721 \pm 0.797^{* * *}$ \\
Width (W) & $8.296 \pm 0.261$ & $8.593 \pm 0.479$ & $8.844 \pm 0.664$ & $10.972 \pm 0.755^{*}$ \\
\hline \hline
\end{tabular}

Data are means \pm S.E of 5 rats. Significant difference from control at $\mathrm{P}<0.05^{*}, 0.01^{* *}, 0.001^{* * *}$

Change $\%$ as compared to control value.

It is generally accepted that at constant hematocrit and temperature, low shear blood viscosity is primarily determined by erythrocytes aggregation, while high shear viscosity depend on erythrocytes deformability. ${ }^{19}$ Previous report 20 has been shown that several alterations of hemorheological properties may take place as a result of free radicals generated during exposure to radiation, such as lipid peroxidation. For instance, lipid peroxidation result of formation of cross-linkages between red cells or protein molecules and lead to increase of cells aggregation. Radiation oxidative stress causes denaturation and precipitation of hemoglobin. These precipitations reduce the deformability of red cells by attached to the inner surface of the cell membrane. Direct radiation attacks on cell membrane leads to increase in the rigidity of the lipid bilayer and aggregation of membrane proteins..$^{21}$ The formation of aggregates (clot) in blood films are observed with $\mathrm{Rn}$ inhalation in our previous work. ${ }^{22}$ The increase in blood viscosity may result in tissue damage by slowing the circulation of blood, and thus reducing the supply of oxygen and nutrient to the tissue cells.

\section{The osmotic fragility of the membrane}

It is clear from the Figure 6 that, the characteristic osmotic fragility curves of irradiated groups shift to the left of the control curve. The dispersion of hemolysis (S) increased, at the same time an average osmotic fragility $\left(\mathrm{H}_{50 \%}\right)$ decreased as show in Table 4. 


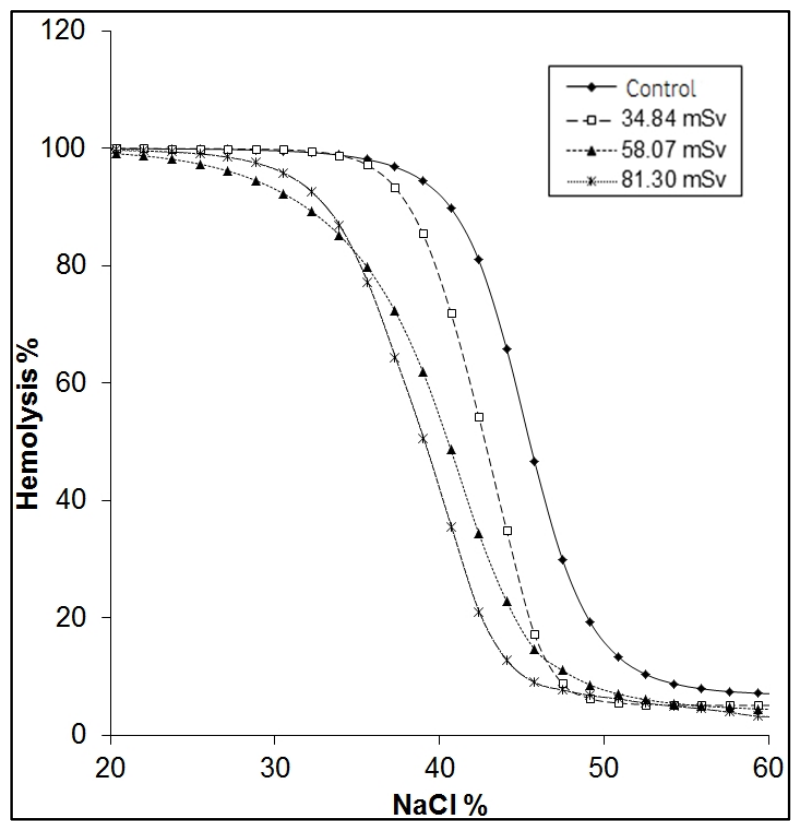

FIG. 6: Osmotic fragility curves for control and irradiated groups.

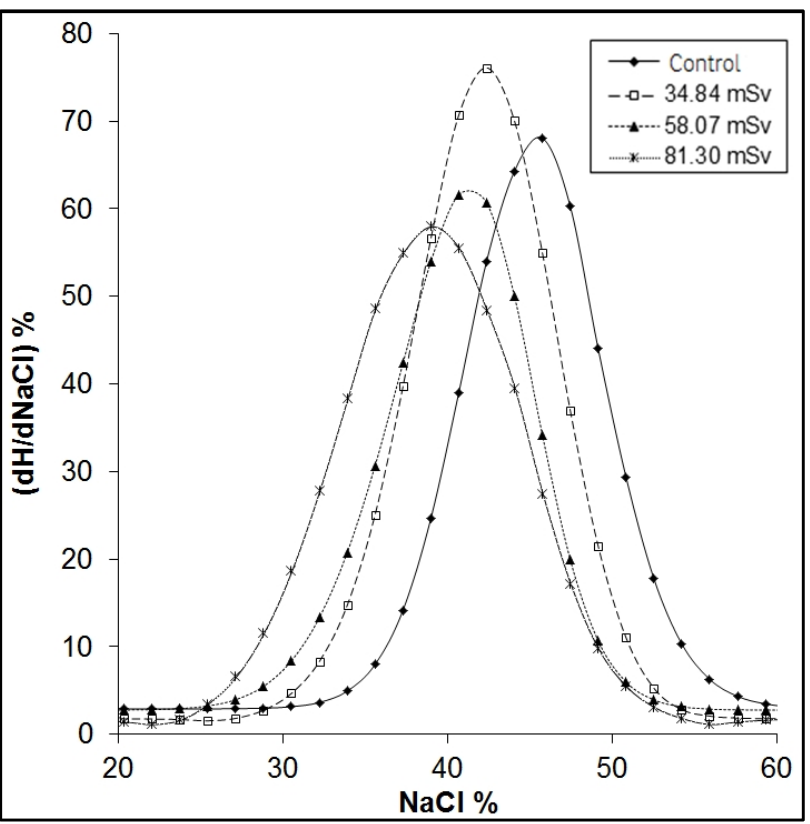

FIG. 7: The rate of hemolysis versus $\mathrm{NaCl}$ concentration for control and irradiated groups.

The increase in the dispersion of hemolysis reflects the radiation-induced irregularity in the erythrocytes membrane as a consequence of alteration in cell permeability, resulting from the radiation-induced irregularity in the erythrocytes membrane. The results obtained from the Figure 7 of the Gaussian distribution curve of the rate of hemolysis indicate decrease in the maximum rate of hemolysis (P) with concomitant shift of the peak center $\left(\mathrm{C}_{\max }\right)$ toward lower values on $\mathrm{NaCl}$ concentration for the irradiated groups. The increase in the width of Gaussian distribution curve for group III indicates increase of cellular membrane elasticity. Manal ${ }^{23}$ obtained the same result in mice after exposed to Rn gas.

The net result of interaction of alpha particles with the biological macromolecules is formed highly energetic active species. These active sites may interact with the adjacent macromolecules causing change in the free motion degree of the hydrocarbons chain and/or the whole phospholipids bilayer macromolecules. Also, unexpected abnormal cross links can be formed between the broken hydrocarbon bonds. ${ }^{21}$ All these possible interactions may be the reason for the changes that occurred in the mechanical properties of cellular membrane.

The change of permeability alters the physiological functions of the RBCs and so disturbs the body functions. In the same time, the increase of RBCs cellular membrane elasticity increases the difficulty of the breaking the old RBCs so that, the life span of the functionless cells is increase.

\section{Conclusion}

From our results, it may be concluded the biological membranes were very sensitive to alpha particles emitted from $\mathrm{Rn}$ gas. Alpha particles changed the mechanical properties of RBCs membrane (permeability and elasticity). This means the low doses of Rn gas are harmful to biological systems and the degree of damage was dose-dependent.

\section{Conflict of interest}

The authors declare that they have no conflicts of interest. The authors alone are responsible for the content and writing of the paper.

\section{References}

1. Felice PD. Primary standards of radon. Metrologia 2007; 44: S82-6.

2. Jostes RF. Genetic, cytogenetic, and carcinogenic effects of radon: a review. Mutat Res. 1996;340:125-39.

3. Robertson A, Allen J, Laney R, Curnow A. The cellular and molecular carcinogenic effects of radon exposure: a review. Int J Mol Sci. 2013;14:14024-63.

4. Chen J. Canadian individual risks of radon-induced lung cancer for different exposure profiles. Can J Public Health. 2005;96:360-3.

5. Environmental Protection Agency (EPA). Radiation risk and realities. Natural Radiation. 2006.

http://www.epa. gov/radiation/docs/riskandrealities/rrpage3.html 
6. Ye W, Sobue T, Lee VS, et al. Mortality and cancer incidence in Misasa, Japan, a spa area with elevated radon levels. Jpn J Cancer Res. 1998;89:789-96.

7. Charles MW. Radon exposure of the skin: II. Estimation of the attributable risk for skin cancer incidence. J Radiol Prot. 2007;27:253-74.

8. Nikezić $\mathrm{D}, \mathrm{Yu} \mathrm{KN}$. The influence of thoron and its progency radon measurements with CR-39 detectors in diffusion chambers. Nucl Instrum Methods Phys Res A. 1998; 419:175-80.

9. Maghraby AM, Alzimami K, Abo-Elmagd M. Estimation of the residential radon levels and the population annual effective dose in dwellings of Al-kharj, Saudi Arabia. J Radiat Res. 2014; 7:577-82.

10. Misdaq MA. Bourzik W. Determination of committed effective doses from annual intakes of ${ }^{238} \mathrm{U}$ and ${ }^{232} \mathrm{Th}$ from the ingestion of cereals, fruits and vegetables by using CR-39 and LR-115 II SSNTD. J Radioanal Nucl Chem. 2002; 254:551-5.

11. Nikezic D. Determination of detection efficiency for radon and radon daughters with CR 39 track detector - a Monte Carlo study. Nucl Instrum Methods Phys Res A. 1994; 344:406-14.

12. Mansy M, Sharaf MA, Eissa HM, et al. Theoretical calculation of SSNTD response for radon measurements and optimum diffusion chambers dimensions. Radiat Meas. 2006; 41: 222-8.

13. Planinić J, Faj Z. Equilibrium factor and dosimetry of Rn by a nuclear track detector. Health Phys. 1990;59:349-51.

14. Qureshi AA, Kakar DM, Akram M. et al. Radon concentrations in coal mines of Baluchistan, Pakistan. J Environ Radioact. 2000; 48: 203-9.
15. Nikezic D, Lau MF, Yu KN. Comparsion of dose conversion factors for radon progency from ICRP 66 regional and an airway tube model of tracheo-bronchial tree. Radiat Environ Biophys. 2006; 45:153-7.

16. Macosko CW. Rheology: Principles, measurements and applications. Wiley-VCH, New York, 1994.

17. Dacie J, Lewis SM. Practical hematology. $6^{\text {th }}$ ed, Churchill Livingstone, New York 2006.

18. Dobrovol'skii NA, Lopukhin YM, Parfenov AS, Peshkov AV. A blood viscosity analyzer. Biomed Eng. 1997; 31:140-3.

19. Lowe GDO. Barbanel JC. Plasma and blood viscosity. Clinical Blood Rheology. 1998:1-10.

20. Mo J, Fan J, Guo Z, Hunag C, et al. A new hypothesis about the relationship between free radical reactions and hemorheological properties in vivo. Med Hypotheses. 1993;41:516-20.

21. Mohandas N, Clark MR, Jacobs MS, Shohet SB. Analysis of factors regulating erythrocyte deformability. J Clin Invest. 1980;66:563-73.

22. Eissa MF, Fayez MS, Ashour MA. et al. Effects of radon inhalation on some biophysical properties of blood in rats. Fourth international conference in modern trends in physics research (MTPR-2010). Cairo University, Egypt.

23. Manal DM. Measurement and calibration of radon doses inhaled by experimental animals and estimation of the resulting biological effects. Ph. D. Thesis, 2005 Biophysics department, Faculty of science, Cairo University, Egypt. 